\title{
Science Culture, Language, and Education in America: Literacy, Conflict, and Successful Outreach by Emily Schoering. New York, Palgrave Macmillan, 2018. 145 pp. ISBN 1349958131
}

\author{
Einas Albadawi Tarboush \\ The University of Texas
}

Correspondence concerning this article should be addressed to Einas Albadawi Tarboush, University of Texas at San Antonio, San Antonio, TX 78249-3209, United States of America. E-mail: einas.tarboush@utsa.edu

Schoerning's (2018), Science Culture, Language, and Education in America: Literacy, Conflict, and Successful Outreach, addresses the issue of science classes in American schools and gives insights into pedagogical approaches to better develop and cultivate science cultures. The book is based on theories that conceptualize and explain science culture in American schools and examine power dispersion when it comes to science literacy and workforce. By the same token, this book also conceptualizes the relationship between science and religion and how both could reach a compromise. The book provides a profound and insightful explanation and analysis of science classrooms, along with the language and culture of science learning. The author makes clear how these environments operate to either further marginalize or advocate for minority groups in schools. This text is a valuable asset in a time when U.S. schools are emboldened by the detectable increase in the cultural and linguistic variance of their students. It enlightens readers, educators, and policymakers on the dynamics of the most effective science classrooms, along with valuable suggestions to be implemented in practice. The book consists of an easily comprehensible six chapters, thorough references, and an index.

In the first chapter, "Where Are We Now? Where Could We Be?”, Emily Schoerning offers a detailed account of the state of science classrooms in America today, and describes how power is at play when it comes to marginalized groups in these classrooms. To achieve more desirable learning outcomes, the author argues that science should be authentic, and that it should be reflective of real-life circumstances and experiences.

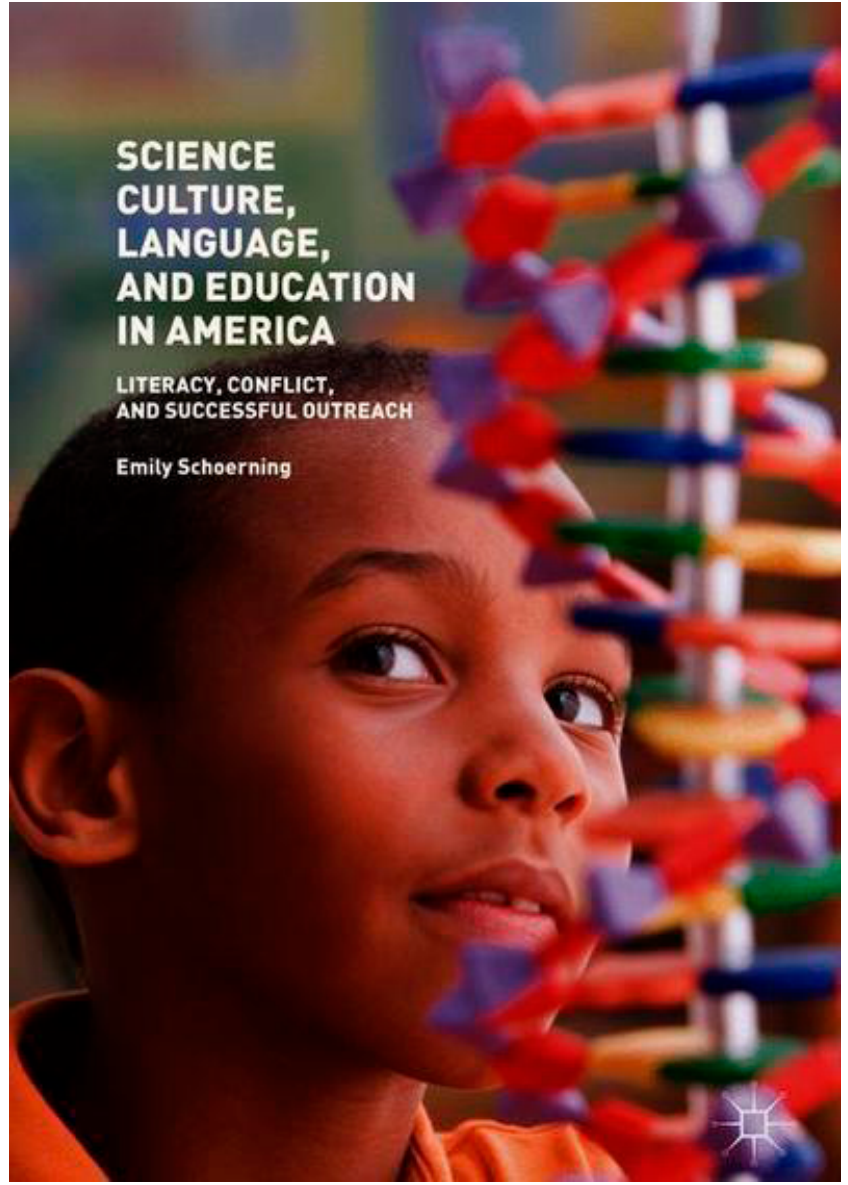

Schoerning argues that in order to achieve equal learning opportunities, the language ideology that surrounds science should be altered and educators should allow students more space to leverage their linguistic repertoire. The question this raises concern 
among educators is that since the STEM (Science, Technology, Engineering, and Math) fields generally yield higher pay for professionals, why aren't more students of marginalized or protected populations striving to proceed in the scientific workforce (Schoerning, 2018)? This is a crucial inquiry that still requires contemplation and investigation.

In Chapter Two, “The Culture of Classroom Science: Discourse, Dialogue, and Language Practices”, the author provides solutions through which educators can allow students to hone in on and properly access the culture of science, instead of just focusing on teaching the language. Schoerning equipped educators with an insightful and practical approach for developing successful science classes. Students should be immersed participants who plan their own learning style, propose their inquiries, and be the active agents of their own science experiments. Schoerning argues that this approach bridges the achievement difference between males and females, and minority and majority groups. It also promotes students' higher cognitive demands, and allows for educational equity through their access of power and agency. As such, the author advocates for students to gain authority as much as their teachers.

In Chapter Three, “Nature of Science Misconceptions: A Source of Cultural Conflict”, Schoerning continues to show the discrepancy between science culture and the actual approach in classrooms. The author criticizes the traditional approach, which is characterized by "memorization" (p. 31). However, she also highlights that unquestionably traditional science has produced great scientists, whose influences are of great importance in the field. Schoerning claims that the transition from the traditional science approach to an approach that is more process-based will not be an easy one.

With Chapter Four, "Culture and Conflict: Science and Social Controversy”, the author continues to show how power is at play in one way or another by demonstrating that most of the beliefs people hold about science are due to some sort of authority. She talks about how misconceptions in science often become re-enforced in children's learning development via “[...] a substantial degree of authority" (Schoerning, 2018, p. 47). The author's main goal is not to criticize such misconceptions; instead, she is arguing that educators should stay critical and develop an awareness of the origin of common science misconceptions. It is vital that, in early childhood education, learners get to know what causes certain misconceptions or occlusions of fact so that later on in life students can comprehend why they are defending or opposing such beliefs installed in themselves. The author uses the figure of the firefighter as a useful example of how or why we build senses of authority when we are young. The crux of this chapter lies in an emergent question: Can we eliminate these misconceptions in our pedagogical approaches? The vast majority of these misconceptions commonly found in science education were taught to us by trusted authority figures, both inside and outside of schools. Realizing later in life, as adults, that we have been influenced by inaccuracies and misconceptions from our schooling makes us question our sources of knowledge. Schoerning argues that such misconceptions are historical, emotional, and socially constructed. Our misconceptions are normalized and internalized to an extent that we don't even realize that we have them. Hands-on activities help students demonstrate how older, commonly held misconceptions are incorrect. The author proposes an emotional approach to address these gaps in knowledge and the misconceptions that have spawned them.

In chapter five, "Science and Religion: Meshing and Conflicting Worldviews", the author strives to show that the conflict between science and religion is not recognized in classrooms often enough, and while the issue may come up in popular media outlets, it is more commonly discussed amongst science professionals. This chapter also shows that people who avoid scientific argument fear social conflict more than they fear scientific conflict. Schoerning also shows how religion and science could live in harmony, which in turn would create a promising platform for more fruitful pedagogies in teaching the sciences.

The sixth and final chapter of this text, "A Case Study in Transforming Communities: The Science Booster Club Program", contains a case study about a woman who established the foundations of the Science Booster Program Club (SBC) that has contributed greatly to developing a science culture that would, "...educate people about what had been seen as highly divisive topics" (Schoerning, 2017, p. 71). The focus of Chapter Six is to show that there is a gap in the literature when examining women in the science workplace and research; however, the study neglected women who are single mothers and financially unsupported. This case study makes up a substantial proportion of Schoerning's text, yet it illuminates critical issues within the process of science learning. 
The principal endeavor of this text is to look closely into the learning ecologies of American science classrooms and mine for new approaches that promote autonomy, authority, and agency amongst science learners. The organization of the chapters and the subsections within each chapter give the book a comfortable sense of flow for better comprehension of the in-depth analyses of science classes, approaches, challenges, and opportunities for future growth. Instead of applying the clutter of in-text citation, Schoerning provided a list of the references used at the end of each chapter.

The question of power was at play throughout the book, whether this power was informational, cultural, or authority-based. White males have largely dominated the field of science in the United States, and if our science professionals intend to be reflective of our thoroughly diverse national population, the teaching of strong science models to minority and protected groups in American schools needs to be a focal point for the educators of today and of tomorrow. Schoerning should have gone into greater depth with regards to the intersectional loci at which the world of science touches the world of politics.

Finally, while the author could have invested more space in the actual techniques by which science educators can help reverse and abolish the scientific misconceptions of the past, this text is still a valuable resource for educators and researchers who are looking to build pedagogy that is both pragmatic and progressive, and tailored to our culturally, linguistically, and economically diverse science classrooms. Schoerning's distinct efforts are appreciated for providing outstanding merit not only for educators and policymakers but also for graduate and undergraduate students in the educational field to comprehend and delve deep into the culture of science in American schools. Also, Schoerning's book is a great standing point for readers to get the basic overview of the dynamic of the culture of science in American schools.

\section{References}

Schoerning, E. (2018). Science Culture, Language, and Education in America: Literacy, Conflict, and Successful Outreach. New York, NY: Palgrave Macmillan. doi: https://doi.org/10.1057/978-1-349-95813-9 